\title{
A ATUAÇÃO NO MERCADO EXTERNO INFLUENCIA A ESTRATÉGIA DE GESTÃO AMBIENTAL DAS EMPRESAS BRASILEIRAS? UM ESTUDO MULTICASO NA INDÚSTRIA CERÂMICA DE SANTA CATARINA
}

\author{
Graziela Dias Alperstedt \\ Doutora em engenharia de Produção pela Universidade Federal de Santa Catarina - UFSC \\ gradial@gmail.com
}

Rogério Hermida Quintella

Doutor em Gerenciamento estratégico pela University of Brighton rhquintella@gmail.com

\author{
Graciella Martignago \\ Mestre em Engenharia de Produção pela Universidade Federal de Santa Catarina - UFSC \\ graci.floripa@gmail.com
}

Sérgio Bulgacov

Doutor em Administração de Empresas pela Fundação Getúlio Vargas - FGV

sergio.bulgacov@fgv.br

\section{RESUMO}

O objetivo geral deste trabalho é analisar a influência da atuação das estratégias de gestão ambiental das maiores empresas cerâmicas brasileiras no mercado externo. Os fundamentos teóricos discutem a gestão ambiental e seus aspectos determinantes, com ênfase nos requisitos e padrões do mercado externo, os quais exigem da empresa nacional seu enquadramento aos ditames de qualidade definidos no país de destino de seus produtos, assim como regulamentações referentes às questões ambientais e atitudes empresariais. A pesquisa foi conduzida por meio de um estudo multicaso, de natureza qualitativa com a utilização de entrevistas semiestruturados e análise interpretativa. Os dados foram organizados seguindo a ordem cronológica, tanto da atuação no mercado externo quanto das práticas ambientais das empresas, com destaque para a visão estratégica da política ambiental das organizações. Apesar da coincidência, em termos de evolução das categorias estudadas (gestão ambiental e atuação no mercado externo), os resultados da pesquisa não permitem afirmar que as estratégias ambientais das empresas tenham sido afetadas por sua atuação no mercado externo. Outros fatores, porém, emergiram como explicações para a estratégia ambiental das empresas, tais como a legislação brasileira e o próprio processo de globalização, levando-as a adotar melhores práticas, contribuindo para manter sua competitividade.

Palavras-chave: Estratégias; Gestão ambiental; Indústria cerâmica; Mercado externo.

\section{IS THE ENVIRONMENTAL MANAGEMENT STRATEGY OF BRAZILIAN COMPANIES INFLUENCED BY EXTERNAL MARKETING PERFORMANCE? A MULTI CASE STUDY IN THE CERAMIC INDUSTRY IN SANTA CATARINA}

\begin{abstract}
The general purpose of this case study is to analyze the influence of foreign market performance on environmental management strategies of the largest ceramic companies of Brazil. The fundamental theories discuss the determining aspects of environmental management, with emphasis on the requirements and standards of the foreign market. The foreign market demands that the domestic companies meet their standard of quality in regard to environmental issues and business attitudes. The research was conducted by means of a multi-case study of a qualitative nature by using semi-structured interviews and interpretive analysis. The data was organized in chronological order for both the performance in foreign markets as well as the environmental practices of the companies, with a focus on the strategic vision of the environmental policy of the organizations. Despite the coincidence of the progress of the studied categories (environmental management and foreign market performance) the results of the study do not affirm that environmental strategies of companies have been affected by foreign market performance. Other factors, however, arose as explanations for environmental strategies of the companies, such as Brazilian legislation and globalization, leading to the adoption of better practices to maintain a competitive edge.
\end{abstract}

Key words: Ceramic industry; Environmental management; Foreign market strategies. 
A atuação no mercado externo influencia a estratégia de gestão ambiental das empresas brasileiras? Um estudo multicaso na indústria cerâmica de Santa Catarina

\section{INTRODUÇÃO}

A preocupação da sociedade em relação ao ambiente natural e às ações das empresas quanto a sua degradação têm crescido nos últimos anos. Apesar do debate acerca dos limites do planeta terra não ser recente, as pesquisas e os estudos sobre esse assunto também têm sido intensificados recentemente em razão da necessidade crescente de se minimizar os impactos negativos da atividade econômica sobre o ambiente natural. Diante do contexto de sobrecarga de demandas ambientais e do crescente impacto da opinião pública, emerge a preocupação da iniciativa privada com a sustentabilidade do planeta, tendo em vista a importância de suas ações sobre os recursos naturais exploráveis e destes para a sustentabilidade da atividade empresarial. Neste contexto, investigar as diversas motivações, internas e externas, que levam as empresas a buscarem uma nova postura diante desses desafios ambientais, parece ser uma tarefa instigante.

Apesar desses fatos, constata-se que muitas empresas desenvolvem estratégias de gestão ambiental apenas voltadas ao atendimento das regulamentações governamentais ou ao processo competitivo internacional, incluindo aí as restrições impostas pelos diferentes mercados. Este último aspecto se constitui o foco deste trabalho (Darnal, Henriques \& Sadorsky, 2008; Eidat, Kelly \& Roche; Eyadat, 2008; Lee \& Rhee, 2006).

Nas cinco décadas anteriores ao ano 2000, a chamada globalização representou um aumento no volume de exportações mundiais da ordem de 16 vezes, sendo que a exportação global de produtos manufaturados cresceu 31 vezes nesse mesmo período (Harrison, Dalkiran \& Elsey, 2000). Nos últimos anos, esses números cresceram proporcionalmente ainda mais. Esta rápida expansão trouxe consigo um aumento da competição, levando as empresas a se conscientizarem sobre a importância da busca de novos mercados. Entretanto, esse movimento as expuseram a uma série de restrições no que tange ao meio ambiente natural, particularmente em relação às exportações das organizações de países emergentes para os países considerados desenvolvidos.

Para competir no mercado internacional, as empresas necessitam se adequar às regras impostas não apenas pelas regulamentações governamentais, mas também pelas exigências da sociedade e pela própria cultura de seus novos mercados (Turolla; Lima, 2010), o que abre a possibilidade de um processo de aprendizagem que, por sua vez, pode ser vantajoso para seus próprios mercados internos. O ingresso das empresas no mercado internacional impõe a necessidade de padronização e certificação de sistemas de gestão ambiental. Esse fato pode levar a diferentes abordagens/estratégias, já que as empresas tendem a reagir buscando garantir sua legitimidade e reputação quanto ao ambiente internacional (Alperstedt, Quintella \& Souza, 2010). Assim, pode-se pressupor, tal como atestado por Qi, Zeng et. al. (2011), que o aumento gradativo das operações internacionais das empresas possa influenciar positivamente em suas estratégias de gestão ambiental.

Tendo em vista a problemática apresentada e considerando a importância de se conhecer a realidade do Brasil e, em especial, do estado de Santa Catarina, esta pesquisa se propõe a analisar a influência da internacionalização nas estratégias de gestão ambiental das empresas produtoras de cerâmica catarinenses que atuam no mercado externo. O Brasil está entre os países que lideram a produção de cerâmica no mundo, com destaque para o estado de Santa Catarina. Este setor se baseia na extração de matérias-primas naturais e nos colorifícios, o que gera importante impacto no meio ambiente natural (Ferrari, 2000). A pesquisa foi conduzida com base em um estudo multicaso em duas empresas cerâmicas catarinenses.

Este artigo contém quatro seções, além desta introdução. A segunda seção apresenta uma breve revisão teórica acerca da gestão ambiental e de sua relação com a atuação das empresas no mercado externo. Na sequência, são descritos os procedimentos metodológicos adotados na pesquisa. Na quarta seção são apresentados e analisados os resultados do estudo, seguidos pelas considerações finais. 


\section{GESTÃO AMBIENTAL E ATUAÇÃO NO MERCADO EXTERNO}

A gestão ambiental pode ser considerada como um conjunto de diretrizes voltadas para as atividades de gerenciamento visando a obtenção de resultados positivos em relação ao meio ambiente, reduzindo ou eliminando os danos ambientais causados pela atividade da empresa (Barbieri, 2006). Uehara et al (2010) destacam o papel plural desempenhado pela gestão ambiental como um instrumento que tem a finalidade de regrar a relação entre a sociedade e a natureza, influenciando as práticas empresariais adotadas e refletindo sua missão e seus valores.

A consideração dos aspectos ambientais na estratégia empresarial tem se configurado em um novo paradigma nos negócios, desvelando benefícios antes não percebidos pelo mundo empresarial, tais como a melhoria da imagem das organizações, a captura de novos mercados, as melhorias no processo produtivo, a economia de insumos, o aumento de rendimentos e a diminuição de desperdícios, além de benefícios para os produtos, tanto na qualidade quanto na redução de custos de embalagens (Hrdlicka, 2009). A ideia de que estratégias possam trazer uma vantagem competitiva para as organizações é a essência da discussão de autores já clássicos como Barney e Hesterly (2007).

Entre as abordagens e os modelos de gestão ambiental existentes, Barbieri (2006) identifica três principais: o controle da poluição, a prevenção da poluição e a incorporação de questões ambientais na estratégia empresarial. Uma taxonomia de cinco estágios num continuum entre ausência e presença de ações de gestão ambiental é apresentada por Hunt e Auster (1990). Já Sanches (2000) classifica as organizações em apenas dois estágios: um reativo e outro proativo. Yang, Yang e Peng (2011) propuseram um modelo gestão ambiental que consiste em três grandes perspectivas: (i) concepção do produto, (ii) processos principais, e (iii) funções de apoio. No modelo, as práticas de gestão ambiental são associadas aos processos, e às funções de apoio, extraídas do modelo de Porter. O modelo também considera o design do produto porque o potencial de reciclagem e de redução de resíduos são determinados na fase de concepção. Hart (1995), com base em sua Visão Baseada em Recursos Naturais, argumenta que existem três recursos estratégicos que podem ser desenvolvidos pelas empresas: prevenção da poluição, gerenciamento de produto e desenvolvimento sustentável. Cada uma delas tem diferentes forças motrizes e se baseia em diversos recursos-chave. Hart e Dowell (2010) revisitam o modelo proposto em 1995 e ratificam sua importância, inserindo questões atuais, tais como as mudanças climáticas.

No que concerne às variáveis estruturais que podem influenciar a implementação de práticas ambientais por parte das empresas, a literatura aponta o tamanho da empresa, o setor industrial, a localização geográfica e o nível de internacionalização (González \& González, 2006).

Entre as variáveis citadas acima, este trabalho se concentra, especificamente, no nível de internacionalização. Nesse sentido, González-Benito e González-Benito (2006) compreendem que as empresas com maior nível de atuação no mercado externo tendem a se beneficiar do conhecimento transferido entre diferentes divisões e plantas, resultando no aproveitamento da adoção de novas práticas tendo como base a experiência de suas unidades mais avançadas ou mesmo em decorrência do processo competitivo internacional ao qual se submetem. Além disso, um maior nível de internacionalização requer a definição de políticas ambientais capazes de responder às demandas específicas dos novos mercados. Por fim, as empresas ligadas a grupos internacionais, devido ao seu tamanho e experiência, podem se beneficiar com alguns dos efeitos dessas características (González \& González, 2006).

Assim, o acesso ao mercado externo exige da empresa nacional seu enquadramento nos requisitos de qualidade definidos no país de destino de seus produtos, assim como regulamentações referentes às questões socioambientais e atitudes empresariais. Nessa perspectiva, a adoção, por parte das empresas, de normas e padrões internacionais pode auxiliar na elevação da competitividade daquelas que valorizam a preservação ambiental e as práticas empresariais responsáveis (Dreher, Amal \& Souza, 2007). 
Tendo em vista essa discussão, Turolla e Lima (2010) consideram que a internacionalização de empresas, seja por meio do comércio exterior ou do investimento direto estrangeiro (IDE), deve ser considerada na análise da sustentabilidade ambiental. Conforme os autores, o World Investiment Report de 2009, publicado pela Conferência das Nações Unidas sobre Comércio e Desenvolvimento (Unctad), divulgou a existência de cerca de 82 mil corporações transnacionais, com 810 mil filiais em todo o mundo. Estas empresas respondem por 33\% das exportações mundiais e empregam 77,4 milhões de pessoas. O estoque global de investimento direto estrangeiro atingiu US\$ 14,9 trilhões em 2008, o que incide diretamente na sustentabilidade, uma vez que o investimento produtivo define as características técnicas da matriz de produção do país, influenciando, por sua vez, no tipo de equipamento produtivo, na sua eficiência energética e em suas características em termos de resíduos e poluição.

Como exemplo prático, uma pesquisa realizada por Cardoso et al (2008) com a Embraer revelou que a pressão do mercado externo é um importante fator de motivação para a evolução da gestão socioambiental da empresa, tanto no que se refere aos clientes e reguladores, quanto aos credores. Dessa forma, a empresa reconhece a necessidade de incorporar a sustentabilidade na estratégia organizacional, com vistas à competitividade internacional futura. Para isso, a área de planejamento acompanha o avanço das demandas mundiais por práticas de gestão mais sustentáveis. Segundo Cardoso et al (2008), as maiores pressões advêm especialmente da comunidade europeia e dos credores internacionais. Todavia, a pesquisa destaca que as práticas de gestão ambiental adotadas no Brasil são transferidas para os sítios produtivos da empresa no exterior, especialmente na China e nos Estados Unidos, porque nesses países a legislação ambiental é menos restritiva se comparadas com a regulamentação brasileira, sendo tais práticas recomendadas por credores internacionais (Cardoso et al., 2008).

Qi, Zeng et. al. (2011) realizaram estudos em todo o Japão e concluíram que, em províncias com maiores taxas de exportação, a adoção da ISO 14.001 é maior, o que indicaria uma maior preocupação com as questões ambientais por parte das empresas que comercializam seus produtos no mercado externo. Outro ponto destacado é que as empresas se beneficiam ao entrar em mercados estrangeiros, ganhando novos conhecimentos com a prática da internacionalização. Neste caso, são citadas as pressões dos clientes estrangeiros como um fator importante na busca de melhores práticas ambientais.

Na mesma linha de pensamento, a pesquisa realizada por González, Sarkis e Adenso-Diaz (2008) levantou, por meio de questionários aplicados em executivos do setor automobilístico da Espanha, a hipótese da influência do grau de internacionalização das empresas na sua gestão ambiental. Os resultados desta pesquisa, porém, revelaram que não houve influência dos processos de internacionalização nas práticas de gestão ambiental desse setor naquele país.

No Brasil, a pesquisa realizada por Hrdlicka (2009) explorou o inverso dessa relação. O autor buscou verificar se o sucesso das exportações de 59 empresas brasileiras foi decorrente de sua responsabilidade ambiental. Seus achados revelaram um nível de significância reduzido para essa relação, ou seja, embora as empresas brasileiras obtenham sucesso no exterior, a influência da adoção de boas práticas de gestão ambiental apresentou baixo impacto explicativo nesse processo. O autor destaca que a maior preocupação da questão ambiental nas empresas é, justamente, adaptar os produtos exportados às exigências da legislação ambiental de cada país importador. Ele observa que a exportação pode levar as empresas a desenvolverem responsabilidade ambiental e a buscarem o melhoramento de suas práticas. Todavia, constatou que o inverso não é verdadeiro, ou seja, boas práticas de gestão ambiental não garantem o sucesso das exportações.

Por outro lado, em um movimento oposto aos trabalhos e pressupostos até aqui apresentados, encontra-se na literatura registros de migração de indústrias para países menos desenvolvidos em busca de menores exigências no processo de produção e de cuidados ambientais. Países desenvolvidos, muitas vezes, também deixam de abrigar determinadas indústrias por pressionarem estas a adotar posturas mais responsáveis em relação ao meio ambiente (Turolla \& Lima, 2010). 
Um trabalho patrocinado pelo Fundo Mundial pela Natureza e desenvolvido por dois pesquisadores da Universidade Tufts, em Massachusetts, nos EUA, revela que existem diversas razões que levam o investimento direto a afetar o meio ambiente. Para Turolla e Lima (2010), o desempenho ambiental das empresas multinacionais, por exemplo, pode estar atrelado às decisões tecnológicas em prol de tecnologias mais limpas ou da manutenção de tecnologias antigas com menor rigor ambiental. Adicionalmente, estas empresas podem estar comprometidas globalmente com altos padrões de gestão de qualidade ambiental ou, em algumas operações específicas, relaxar nesses métodos de gestão. Apesar do papel crescente desempenhado por ONGs, que pressionam as multinacionais por maior uniformidade em relação aos padrões ambientais mais exigentes, parece não haver evidência significativa de que, na média, as multinacionais possam trazer avanços em relação às práticas locais. Há, entretanto, bons casos de grupos empresariais que levam boas decisões tecnológicas, assim como boa gestão ambiental, até suas subsidiárias, em várias partes do mundo.

Uma segunda razão que explica os impactos do IDE na área ambiental diz respeito à produtividade e ao crescimento econômico. O IDE produz o efeito de espalhar tecnologias e métodos de gestão em vários destinos ao redor do mundo, contribuindo para que obtenham ganhos de produtividade. Para os economistas, principalmente neoclássicos, esses ganhos de produtividade correspondem às economias no uso de recursos, que poupam, inclusive, recursos ambientais. Nesse sentido, o crescimento econômico pode, em alguns casos, atuar em prol do meio ambiente (Turolla \& Lima, 2010).

O IDE pode apresentar, ainda, impacto significativo sobre a regulação ambiental mundial, pois empresas multinacionais podem tentar garantir padrões ambientais mais elevados nos seus mercados-alvo com o intuito de garantir suas vantagens competitivas (Turolla \& Lima, 2010). Esse fato foi verificado por Cardoso et al (2008), que constataram, no caso da Embraer, que um dos fatores motivadores para a evolução da gestão ambiental da empresa foi, justamente, a pressão do mercado externo, especialmente o europeu. Nesse sentido, os autores perceberam uma intensa preocupação da empresa com o impacto da indústria no ambiente natural, especialmente em razão da presença de produtos químicos utilizados na manufatura dos aviões.

Pode-se verificar, entretanto, a possibilidade oposta: a competição pelos investimentos diretos pode levar a padrões ambientais menos rigorosos. Uma importante questão que se situa na relação entre internacionalização e sustentabilidade é a hipótese da existência do efeito conhecido como "paraíso de poluição". Neste cenário, as indústrias mais intensivas em poluição podem migrar dos países mais desenvolvidos, que tenham padrões ambientais mais rigorosos, para os menos desenvolvidos, que, por sua vez, são mais flexíveis nesse aspecto (Turolla \& Lima, 2010).

Apesar dos argumentos descritos anteriormente, Turolla e Lima (2010) atentam para a inexistência de estudos conclusivos sobre o efeito da internacionalização na sustentabilidade. As razões para isso são tanto a complexidade do tema quanto sua recente abordagem. Esperam, assim, que o aumento da internacionalização possa afetar positivamente a preocupação com a sustentabilidade, mas ainda não é possível se ter certeza sobre isso. É nesse sentido que o trabalho aqui apresentado tenta avançar.

\section{O MERCADO MUNDIAL DO SETOR CERÂMICO E SEUS IMPACTOS AMBIENTAIS}

O mercado mundial de revestimentos cerâmicos é liderado pela China, tanto na produção e no consumo de cerâmica quanto no crescimento das exportações. Os principais produtores, na sequência, são Brasil, Índia, Irã e Itália, respectivamente. Já quando se trata de exportação, o Brasil aparece como quinto no ranking. Em primeiro lugar figura a China, seguida pela Itália, Espanha e Turquia (Anfacer, 2011). Esses dados indicam que o Brasil está entre os países que lideram a produção e o consumo de cerâmica no mundo, mas sua posição desce de segundo para quinto lugar quando se trata de exportação.

Revista de Gestão Social e Ambiental - RGSA, São Paulo, v. 7, n. 2, p. 3-19, maio/ago. 2013. 
Em 2011, as vendas totais do setor no país atingiram 834,7 milhões de metros quadrados, sendo 774,7 milhões vendidos no mercado interno e 60,1 milhões exportados. Atualmente, o mercado internacional de revestimentos cerâmicos continua sofrendo os reflexos da conjuntura econômica mundial, ainda não estabilizada, após a crise de 2008. Desde então, as exportações declinaram em quase 20 milhões de metros quadrados e se comparadas ao ano 2006 sofreu uma queda de 52 milhões.

Entretanto, segundo a Anfacer (2011), a produção e o consumo mantidos pelos países emergentes, especialmente no setor da construção civil, e os sinais de recuperação do mercado americano, tendem, no entanto, a apresentar cenários mais otimistas nos próximos anos. Destaca-se, no setor, a participação de novos países, tanto produtores quanto consumidores, que passam a integrar o grupo dos principais players do segmento, tendência que vem ocorrendo nos últimos anos.

Outra questão que chama atenção é o contínuo desenvolvimento tecnológico da indústria cerâmica mundial, a disseminação do uso de cerâmica em diferentes aplicações e ambientes e a crescente incorporação do conceito de sustentabilidade no setor (Anfacer, 2011). No que tange à questão ambiental, a produção de cerâmica baseia-se na extração de matérias-primas naturais e nos colorifícios, o que provoca um impacto considerável no meio ambiente natural (Ferrari, 2000). Na fabricação de cerâmica, são utilizados como insumos água, energia e matérias-primas tóxicas.

A água é usada em grande quantidade em quase todas as etapas do processo de fabricação dos produtos cerâmicos, sendo que sua qualidade é essencial na preparação da argila e de esmaltes líquidos, nos corpos de argila para extrusão e moldagem, e na moagem por via úmida.

A energia, em função da necessidade de queima de seus produtos, também é muito consumida pela indústria cerâmica, com uso, principalmente, centrado nos processos de secagem e queima, sendo o gás natural e o gás liquefeito de petróleo (GLP) empregados na maioria das empresas. A energia elétrica, por sua vez, é empregada nas instalações e nos maquinários usados para a moagem, mistura das matérias-primas e para a conformação das peças, sendo consumida em quantidade bastante inferior àquela dos combustíveis.

Embora a principal matéria-prima da indústria cerâmica (argila) seja um recurso mineral primário, extraído diretamente da natureza, existem alguns produtos empregados em sua manufatura que podem oferecer efeitos relativos à toxicidade de seus constituintes. No processo de preparação do esmalte são introduzidos na suspensão um ou mais produtos químicos com o objetivo de alcançar ou corrigir determinadas características. Entre eles podem ser citados os ligantes, os plastificantes, os defloculantes, os fluidificantes e os antiespumantes. Além destes aditivos, para coloração aos esmaltes, são utilizados corantes (Ferrari, 2000).

No que se refere às emissões atmosféricas, o setor cerâmico é responsável por emitir material particulado composto por metais, além de outros poluentes inorgânicos, tais como os fluoretos. Assim, o manuseio e o processamento da argila e de outras matérias-primas originam a formação de pós os quais podem ser dispersos no ar, causando problemas respiratórios. A geração desse material particulado também pode estar associada ao transporte da argila em caminhões sem a proteção de coberturas, ao armazenamento da argila fora de silos ou galpões, à preparação da massa cerâmica (principalmente na via seca), além dos processos de moagem, peneiramento, atomização (na via úmida) e na secagem. Outras formas de gerar essas partículas podem advir da preparação do esmalte, nas fases de mistura, moagem e aplicação por spray, nas operações de decoração, na queima e no acabamento das peças. O processo de combustão de energéticos também pode provocar a dispersão dessas partículas quando as empresas utilizam óleo ou lenha nos fornos e/ou secadores (Ferrari, 2000).

Já os compostos gasosos liberados durante a secagem e a queima são provenientes, principalmente, dos compostos das matérias-primas. Todavia, os combustíveis também podem contribuir para a emissão desses poluentes gasosos (Fiesp, 2008).

No que tange aos ruídos e a vibração, as principais fontes estão relacionadas com as instalações de moagem, mistura e prensagem. As atividades de transporte de caminhões, tanto de 
matérias-primas, quanto de produtos ou resíduos também podem ser consideradas motivo de incômodo para a comunidade circunvizinha à empresa.

A geração de efluentes líquidos nos processos cerâmicos, por sua vez, é proveniente, principalmente, da água utilizada na limpeza das unidades de preparação, nos moldes de fundição, nos processos de esmaltação, engobe e na decoração. Os sistemas de controle de poluição por via úmida (lavadores de gases) também podem ser responsáveis pela geração de efluentes, além do uso sanitário.

Quanto aos resíduos sólidos, as atividades do setor geram resíduos oriundos de várias operações e possuem características diversas. São eles os lodos provenientes da decantação do tratamento de efluentes líquidos, os cacos de cerâmica crus, os cacos de cerâmica queimados, as embalagens usadas, os tambores, bem como as bombonas contaminadas. Se esses resíduos forem jogados diretamente sobre o solo poderão resultar na sua contaminação, assim como dos lençóis freáticos pela infiltração de metais pesados, como chumbo e zinco, levados pela chuva.

Pode ser considerada ainda como impacto ambiental, a geração de resíduos das embalagens, tais como as caixas de papelão, os sacos, os galões plásticos e os tambores e bombonas dos produtos químicos que também podem causar danos ao meio ambiente pelo potencial de contaminação do solo e das águas subterrâneas. Neste caso, o retorno desses recipientes aos fornecedores ao invés do seu encaminhamento para aterros industriais seria o ideal. Pelo o que se observa, é evidente a geração de resíduos tóxicos oriundos da produção de cerâmica, que incluem óxido de silício, óxido de cálcio, óxido de zinco, óxido de alumínio, óxido de potássio e óxido de bário (Fiesp, 2008).

Todos esses impactos, exigem que as empresas do setor tratem a questão ambiental de forma séria e estratégica, pois as operações de mineração e o processo produtivo da cerâmica geram efeitos importantes no meio ambiente.

\section{PROCEDIMENTOS METODOLÓGICOS}

Esta pesquisa foi desenvolvida por meio de um estudo multicaso realizado em duas grandes empresas cerâmicas do estado de Santa Catarina. A escolha pelo setor cerâmico se deu em razão do impacto ambiental do setor e por ser o Brasil, hoje, um dos grandes players mundiais de revestimentos cerâmicos. Santa Catarina tem reconhecimento como polo internacional nesta produção e concentra as maiores empresas brasileiras, entre elas as pesquisadas nesse estudo.

Esta pesquisa caracteriza-se como qualitativa, descritiva e interpretativa, por permitir o conhecimento aprofundado dos principais movimentos de mudanças nas organizações estudadas. Optou-se pelo método de estudo multicaso por se caracterizar como um estudo intensivo, levando em consideração, principalmente, a compreensão como um todo do assunto investigado (Richardson, 1999).

Esta pesquisa tem caráter descritivo, uma vez que se preocupou com a descrição das características do fenômeno em estudo. A característica interpretativa da pesquisa permitiu aos pesquisadores a interpretação dos dados coletados junto aos principais gestores e o acesso a registros internos, aos membros da organização, às minutas de reuniões, além de outros documentos. Por conseguinte, a pesquisa interpretativa favoreceu a maior interação entre entrevistados e entrevistadores (Miller \& Friesen, 1982).

Os dados primários referentes à evolução da gestão ambiental das empresas cerâmicas foram coletados, em maio, outubro e novembro de 2010 junto às empresas aqui denominadas de empresa A e empresa B, por meio de entrevistas semiestruturadas e documentos organizacionais. As entrevistas foram gravadas e duraram, em média, 50 minutos. Foram entrevistados o gerente técnico, a coordenadora de marketing e produto, o diretor comercial e os integrantes das áreas de marketing e ambiental da empresa A, totalizando cinco pessoas, e os responsáveis pelas áreas de exportação (dois entrevistados) e gestão ambiental (dois entrevistados) da empresas B, totalizando quatro pessoas. Portanto, ao todo, foram realizadas 9 entrevistas na sede das empresas em Santa

Revista de Gestão Social e Ambiental - RGSA, São Paulo, v. 7, n. 2, p. 3-19, maio/ago. 2013. 
Catarina. Os entrevistados são pessoas que acompanharam o processo de adaptação do sistema de gestão ambiental ao longo do tempo e o processo de internacionalização das empresas. Durante a estada nas empresas foram visitadas as fábricas onde foi possível observar as práticas de gestão ambiental descritas pelos entrevistados. A observação se deu a dos dados coletados nas entrevistas. Foi possível observar, por exemplo, o aproveitamento da água e dos refugos da produção. Ao longo da visita, anotações de campo foram sendo feitas que possibilitaram a comparação com os dados das entrevistas e dos documentos, em um processo de triangulação, aumentando a validade da pesquisa (Flick, 2009). Os dados secundários foram coletados, principalmente, de pesquisas anteriores e documentos organizacionais disponibilizados pelas empresas. Os dados relativos à evolução da internacionalização das empresas foram extraídos da pesquisa de Alperstedt et al (2010), com o objetivo de traçar um quadro comparativo com a evolução da sua gestão ambiental.

Para a análise, foi utilizada a análise interpretativa dos dados secundários e primários, com enfoque na fala dos entrevistados, buscando identificar a influência da internacionalização da empresa em sua gestão ambiental. Os dados obtidos foram sistematizados de uma lista de eventos ao longo do tempo e organizados em uma figura. Esses dados referem-se as categorias identificadas na literatura sobre gestão ambiental e se relacionam com práticas ambientais (I) reativas, (II) preventivas e (III) antecipatórias interpretadas à luz da taxonomia de Barbieri (2006). Em termos de evolução, o período em vermelho foi classificado como "de controle", o período em amarelo como "prevenção" e o período em verde como "estratégico". Os dados sobre a evolução da internacionalização das empresas foram comparados com os dados sobre a sua evolução na gestão ambiental. Após essa comparação, os dados foram checados com as entrevistas e analisados à luz do referencial teórico.

\section{A EMPRESAS ESTUDADAS E SUA ATUAÇÃO NO MERCADO EXTERNO}

Não se constitui objeto deste trabalho apresentar detalhadamente o processo de internacionalização das empresas estudadas. Todavia, torna-se necessário apresentar a evolução do processo, a fim de buscar argumentos que permitam compará-lo com a evolução da gestão ambiental nas empresas.

Na figura 01, é possível observar, em linhas gerais, a evolução da internacionalização das empresas objeto deste estudo com ênfase nas etapas destacadas, tendo como base estudo de Alperstedt et al (2010).

\begin{tabular}{|lcll|}
\hline Empresa A & & \\
1980 & 1989 & 1992 & 1997 \\
\hline $\begin{array}{l}\text { Fase inicial } \\
\text { Exportação }\end{array}$ & $\begin{array}{l}\text { Segunda fase: } \\
\text { Joint venture }\end{array}$ & $\begin{array}{c}\text { Terceira fase } \\
\text { Estruturação }\end{array}$ & $\begin{array}{l}\text { Quarta fase } \\
\text { Subsidiária de vendas }\end{array}$ \\
Empresa B & & & 1993 \\
\hline 1980 & 1982 & 1991 & Quarta fase \\
\hline Fase inicial & Segunda fase: & Subsidiária de vendas \\
Trading Company & Feiras internacionais & Terceira fase & \\
\hline
\end{tabular}

Figura 1: O processo de internacionalização das empresas cerâmicas catarinenses.

Fonte: Alperstedt et al (2010)

A internacionalização das duas maiores empresas cerâmicas catarinenses foi iniciada com exportações esporádicas direcionadas às demandas de países da América Latina, como respostas à situação econômica da década de 1980. Tais países apresentavam baixa distância psíquica, sendo que, somente posteriormente, tiveram início as exportações para os Estados Unidos. 
Impulsionadas pelo incremento das exportações, tais empresas tiveram seus processos de internacionalização modificados ainda naquela década. As próximas etapas foram marcadas por uma maior preocupação com a expansão externa, saltando de um comportamento gradual e esporádico para fases mais planejadas, chegando a estabelecer subsidiárias de vendas nos Estados Unidos, ambas na década de 1990 (Alperstedt et al, 2010).

\section{A GESTÃO AMBIENTAL DAS EMPRESAS ESTUDADAS}

De acordo com os dados primários, em 1979 deu-se o início da produção de cerâmica pela empresa A. O entrevistado B relatou que, naquela época, praticamente, não existiam exigências com relação ao meio ambiente. Por consequência disto, os resíduos gerados no processo produtivo não eram segregados e não havia grande preocupação com o seu reaproveitamento na empresa, tampouco com o controle da poluição atmosférica. Os processos de tratamento ambiental existiam, mas eram ainda embrionários, "como eram também nas demais empresas brasileiras".

A implementação de ações de gestão ambiental na empresa A teve seu início na década de 1990, com o intuito de atender à legislação nacional, que, nessa época, estava se desenvolvendo no Brasil. Neste primeiro momento, a empresa procurou, de forma reativa, atender as leis federais e estaduais, porém, como a própria legislação estava se consolidando, não havia ainda um panorama ideal e claro a seguir. As exigências eram tidas como burocracias com alto custo de atendimento.

A empresa passou, assim, por mais de dez anos sem ter a gestão ambiental como uma de suas preocupações principais, fato este que, na época, era comum e generalizado no país, por conta da falta de uma cultura de preocupação ambiental estabelecida.

Uma das ações com vistas ao controle de poluição foi a criação da estação de tratamento de água a qual, posteriormente em 1993, recebeu melhorias objetivando minimizar os efeitos negativos ao meio ambiente.

Embora as primeiras ações ambientais tivessem como principal motivador o atendimento à legislação, a empresa, aos poucos, entrou na segunda abordagem descrita por Barbieri (2006), criando melhorias que colaboraram com a prevenção, mesmo que motivada principalmente pela questão econômica.

Uma vez adotadas as novas práticas de gestão ambiental, ocorreram mudanças das fontes energéticas da empresa, buscando-se opções menos poluentes. Assim, em 1996, a empresa deixou de usar o carvão vegetal dentro de sua fábrica e passou a utilizar o carvão mineral. Inicialmente como uma medida econômica, a mudança foi capaz de reduzir a poluição gerada. Em 1999, outra mudança foi realizada. Também movida por questões econômicas, a empresa decidiu substituir o carvão pelo gás GLP, e, posteriormente, pelo gás natural.

A escolha do uso do carvão, até então, se dava pelo fato de ser uma fonte barata, pela proximidade com uma região carbonífera e ainda pela sobra de carvão - gerada por uma mudança na legislação. Na época, como tantas outras empresas, a Empresa A pagava somente o frete, o que viabilizava o uso dessa fonte de energia. Com o aumento no preço do carvão, iniciaram-se buscas por outras fontes energéticas. Embora o gás seja mais caro, se comparado ao carvão, viabilizaram o seu uso e os benefícios proporcionados por essa iniciativa foram: a manutenção e o controle do processo. Mesmo com foco na otimização financeira, as melhorias implementadas começaram a criar resultados positivos em relação à questão ambiental, desenvolvendo novos pontos de vista em relação às políticas relacionadas ao meio ambiente.

Os entrevistados apontaram que o ano de 2000 configurou uma grande mudança no que se refere às exigências feitas pelos órgãos ambientais, chegando, segundo eles, a uma equiparação da legislação brasileira com à de países de primeiro mundo. Até o ano de 2004, foram realizadas ações pontuais de melhoria, já que a empresa acreditava ter uma boa prática ambiental. Depois de 2005, as adequações realizadas na política ambiental passaram a visar não só o ganho econômico e a otimização dos processos, mas também a sustentabilidade de uma forma mais ampla. Neste mesmo 
ano, a empresa implantou um circuito fechado de calor - antes jogado para a atmosfera - obtendo assim dois ganhos: um ambiental e outro financeiro.

Assim como o calor desperdiçado, grande parte da água proveniente do processo produtivo também era jogada fora. Esse cenário se reverteu em 2006, quando foi adotado o fechamento do circuito hidráulico. Até então não existia legislação que controlasse este processo, mas, em 2005, esta questão se tornou mais presente nas demandas ambientais, exigindo da empresa uma nova postura. Após a implantação de tal melhoria, $100 \%$ da água passou a ser reaproveitada e, mesmo com um custo inicialmente alto para readequação do processo, os resultados, segundo os entrevistados, foram compensadores.

No que se refere ao reaproveitamento de água, o ganho econômico é proporcionado, por um lado, pela captação de água da fonte e, por outro, pela utilização dos resíduos retirados, como restos de argila, carregados pela água resultante do processo de produção, os quais passaram a ser também reaproveitados, gerando economia em matéria-prima.

Outra melhoria diz respeito ao caco cerâmico. Antes visto apenas como refugo de processo, este passou a ser reutilizado junto a outros materiais, compondo cerca de $18 \%$ do material total utilizado. Com isso são reaproveitadas, aproximadamente, 10.000 toneladas/mês, valor que representa cerca de $25 \%$ de matéria-prima que retorna ao processo.

Quanto aos resíduos gasosos, são emitidos, basicamente, CO2 e água. Todavia, mesmo utilizando gás natural como fonte de energia, a empresa não consegue obter crédito de carbono, pois essa prática já existe há mais de 10 anos, o que não confere à empresa o direito retroativo de ganhar este crédito.

Com relação ao conceito dos produtos, a empresa também inovou ao desenvolver um porcelanato que proporciona imitações realísticas de mármore e, posteriormente, madeira. Os entrevistados acreditam que, ao fabricar pisos que reproduzem produtos naturais, a empresa contribui para minimizar a extração destes. Desta forma, a variável ambiental aparece sendo utilizada também como estratégia de venda.

Para economia de sua principal matéria-prima, a Empresa A realizou em 2004, em parceria com uma universidade, um projeto para recuperação de jazidas de onde é extraída a argila. Da argila utilizada pela empresa, $90 \%$ vem de jazidas de terceiros, espalhadas por todo o país, sendo $10 \%$ proveniente de mineradora própria.

A reparação do solo das áreas de extração é realizada por meio da plantação de soja, quando ocorre em área previamente agriculturável, ou reflorestamento, no caso de existência prévia de mata nativa, logo após a retirada do tapete e da extração da argila. A formação de pastagens não é uma das opções da empresa por ser percebida por ela como ambientalmente mais degradante. Quanto às espécies que vivem no local, estas são retiradas, encaminhadas para os viveiros e depois recolocadas no ambiente novamente.

De acordo com o entrevistado $\mathrm{A}$, nas atividades relacionadas à mineração, a empresa desenvolve pesquisas e prospecção, extração, operação, manejo e recuperação das áreas mineradas de matérias-primas. As áreas são mineradas após o detalhamento de um plano técnico e econômico para a recuperação da paisagem alterada pelo processo de extração. No contrato de arrendamento da terra, dependendo da situação, o terreno é devolvido até mesmo em melhores condições para o proprietário, reflorestando as áreas exploradas com a mata nativa encontrada em seu estado inicial.

Quando questionados sobre a inexistência de certificação ISO 14.001, o entrevistado B afirmou que tal certificado é ainda opcional para o mercado cerâmico, pois não há pressão institucional nesse sentido. Além da questão de mercado, o entrevistado destaca também a necessidade de considerar o alto investimento que uma certificação deste nível exige, pois o custo de adequação do processo produtivo é alto. A ISO 14.001 exige investimentos constantes, o que, no momento, está sendo focado para a certificação de qualidade (ISO 9.001). Além disso, segundo o entrevistado, a ISO 14.001 dependeria de um esforço corporativo muito intenso, o que no momento é direcionado para a questão de produtividade e de qualidade da companhia. 
Por sua vez, a empresa B foi fundada em 1960, mas somente no início da década de 1990 a preocupação ambiental começou a aparecer nas suas principais decisões. $O$ foco da gestão ambiental, naquele momento, era o controle dos resultados do processo produtivo (posicionamento que imperou até por volta de 2000). Esta postura verificada pode ser relacionada à etapa inicial do modelo de gestão ambiental, proposto por Barbieri (2006).

Inicialmente, a empresa apenas cumpria o exigido pela legislação, que, por sua vez, não era muito efetiva, tratando e reaproveitando alguns poucos resíduos.

Em 1995, também ocorreu a otimização das unidades fabris, com o fechamento das unidades de Minas Gerais, Paraná e Espírito Santo, concentrando-as então em Santa Catarina e, posteriormente, na Bahia (já nos anos 2000). Neste momento, teve início também a coleta seletiva de papel, plástico e material orgânico, cujo destino foi direcionado às empresas recicladoras licenciadas.

Apenas em 1996 foi implantada a estação de tratamento de efluentes, substituindo a técnica até então utilizada de bacias de decantação. Logo depois disso, o processo foi automatizado e, no ano 2000 , a água passou a ser $100 \%$ reaproveitada no processo de produção.

Ainda em 1996 a Empresa B alcançou a certificação da ISO 14.001, sendo, segundo o responsável pela gestão ambiental, "a primeira cerâmica no mundo a obter esta certificação", mesmo que o mercado não demandasse por isso. A partir de 2001, a certificação não foi renovada, mas a empresa manteve os padrões já alcançados. Segundo os entrevistados, além do custo da renovação da certificação, os clientes no exterior utilizam seus checklists próprios, processo que ocorre até os dias atuais.

$\mathrm{O}$ ano de 2000 parece ter sido um divisor de águas para a empresa B, pois sua visão em relação à gestão ambiental modificou-se por conta dos ganhos econômicos dela oriundos. Isto motivou a continuidade do processo e possibilitou posturas mais preventivas, enquadrando-se na segunda etapa prevista por Barbieri (2006), caracterizada por modificações no processo e produto, reduzindo o desperdício e acarretando na redução de custos. Neste momento, algumas técnicas de produção mais limpa passaram a se tornar projetos prioritários. A empresa passa a lidar, então, com um fator limitante à melhoria no processo produtivo: a cultura do reaproveitamento de resíduos.

Nesse momento, coube à empresa provar que essa medida não tiraria a qualidade daquilo que era produzido, realizando testes por meio do departamento de tecnologia cerâmica. Assim, os primeiros estudos de utilização de resíduos começaram a acontecer em 2004, sendo estes reciclados aos poucos por meio de sua adição à matéria-prima virgem. Dessa forma, foram sendo adicionados $0,5 \%$ de material reutilizado por vez, num trabalho de verificação, passo a passo.

Também no ano de 2000 a empresa passou a adotar o reaproveitamento do lodo da estação de tratamento. Esse lodo, gerado no processo de polimento, é composto, em grande parte, por argila. Já o lodo do porcelanato passou a ser vendido para empresas que o utilizam na composição do cimento.

A partir dessa experiência a empresa passou a realizar um trabalho com olarias e cimenteiras, com o objetivo de reaproveitar ao máximo seus resíduos. Para tal, a organização precisou ainda enfrentar uma questão legal, uma vez que, até então, não existia legislação que previsse o uso dos resíduos da indústria cerâmica para outros fins. Para solucionar este problema, as empresas do setor agiram em conjunto, frente a instituições, tais como o Sindicato das Cerâmicas e a Federação das Indústrias, iniciando um trabalho para derrubar esse impeditivo legal. Para isso foram desenvolvidos estudos que comprovaram que era possível utilizar resíduo cerâmico sem prejuízo de qualidade do produto final. Finalmente em 2008/9 o Conselho Estadual do Meio Ambiente (Consema) - aprovou a utilização dos resíduos, criando uma resolução que passou a permitir tal prática. Desta forma, os resíduos sólidos que antes representavam custos, passaram a gerar receita para a empresa.

Quanto às áreas de mineração de sua principal matéria-prima, a argila, 50\% delas são de propriedade da empresa, sendo os $50 \%$ restantes comprados de terceiros. Como solução para o desgaste do solo, a Empresa B realiza lavras simultâneas ao processo de recuperação. Nos solos 
terceirizados, a empresa busca por áreas de pinus, eucalipto ou área agriculturável e preocupa-se em dar um uso futuro para tal espaço.

Tratando-se da lavra, a legislação é rigorosa, fazendo cobranças e exigências as quais obrigatoriamente devem ser cumpridas. Essas práticas são exigidas pelos órgãos ambientais desde 1996 e, novamente, neste aspecto, os entrevistados apontam que as leis foram o ponto de partida para as melhorias de processo que realizam.

A Fundação do Meio Ambiente começou a atuar de forma mais efetiva na década de 1990, fato que acabou por levar a empresa a buscar melhores padrões de gestão ambiental. Para minimizar as emissões atmosféricas, a Empresa B implantou um sistema de lavador de gases e filtração, sendo este último implantado no ano de 2000. No que diz respeito aos seus combustíveis, a Empresa B também usa gás natural, gerando efluentes gasosos em padrões, segundo os entrevistados, aceitáveis.

Outra inovação relaciona-se ao calor necessário para secar a massa. A equipe de produção da empresa verificou que a presença da chama era desnecessária, necessitando somente de calor e, com isso, a chaminé de um forno poderia ser desviada. Consequentemente, o calor que antes era desperdiçado, passou a ser reaproveitado no processo produtivo.

A questão ambiental também parece ser trabalhada com os funcionários: "A gente procura fazer educação ambiental, por que não adianta ter o maior centro de triagem, por exemplo, se não tiver educação ambiental". Segundo os entrevistados, as informações ambientais da empresa estão inseridas no sistema de informação gerencial, sendo acessíveis por todos os funcionários. Com relação aos produtos ecológicos, hoje a Empresa B trabalha com três linhas, o Ecostone, porcelanato que reutiliza $60 \%$ de materiais reciclados; o Ecocement, classificado como um azulejo, e o Crossville. O Crossville reutiliza, em média, $18 \%$ da matéria-prima advinda de quebras. Além das quebras, são reutilizados materiais com defeito, sobras de massa e o lodo da estação de tratamento de efluentes. A empresa adota o processo ecológico como recurso para a venda, embora todos os produtos tenham, em maior ou menor grau, materiais reciclados. Para ter produtos com o apelo ambiental como diferencial, certifica-se alguns que merecem destaque na estratégia de marketing.

$\mathrm{Na}$ Empresa B, a gestão ambiental faz parte da estratégia, sendo pré-requisito da análise de projetos novos e apelo de venda (estratégia de marketing). A motivação de continuar neste caminho, segundo os entrevistados, vem do reconhecimento do mercado, como o prêmio Fritz Muller, concedido pela Fundação do Meio Ambiente de Santa Catarina (Fatma), recebido em 2009, o qual reconhece os melhores projetos voltados ao meio ambiente no estado.

Um resumo da gestão ambiental das empresas pode ser observado na figura 2. 


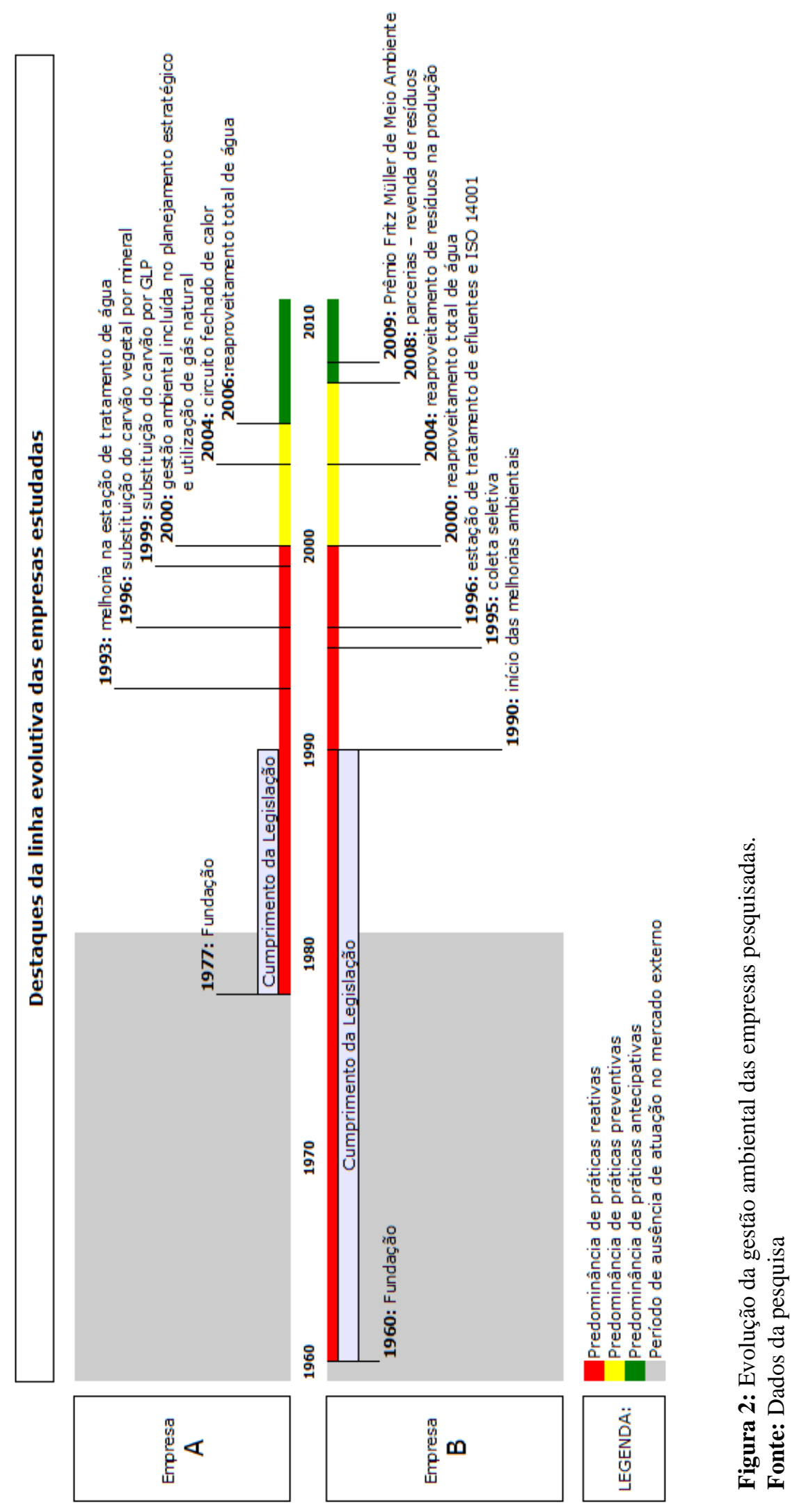


Observa-se que os períodos em vermelho se referem à adoção de práticas de remediação e controle por parte das empresas. Os períodos em amarelo retratam períodos de prevenção. Já os períodos em verde caracterizam-se por apresentarem uma visão estratégica da gestão ambiental das empresas.

\section{A INFLUÊNCIA DA INTERNACIONALIZAÇÃO NA GESTÃO AMBIENTAL DAS EMPRESAS}

Com relação às exigências do mercado internacional, os entrevistados ressaltam que o mercado americano exige critérios que se adéquam ao Green Building. Sugerem que as exigências na exportação aparecem muito mais por parte dos usuários finais do que de legislações internacionais específicas. Ressaltam que os clientes não exigem certificação e que preferem, eles mesmos, auditarem a empresa por meio de questionários que focam principalmente na origem do produto e de suas matérias-primas. Assim, as certificações deixaram de ser exigidas pela maior parte dos países que importam os seus produtos e os próprios clientes sabem o custo que a certificação acarretaria no produto, optando, então, pelos seus próprios checklists.

No início, as empresas viam o mercado externo mais evoluído em relação ao interno quando o assunto era a legislação e a demanda comercial. Todavia, hoje, acreditam que as demandas nacionais e internacionais estão bastante equilibradas. Como já citado, a maior pressão sentida de país importador de produtos das empresas provém dos EUA, em razão das exigências e da realização de auditorias.

Os entrevistados apontam que no mercado interno, atualmente, as exigências dos clientes estão começando a se equiparar com as do mercado externo. Outro ponto destacado refere-se aos países que buscam inibir a importação, colocando entraves, tornando difícil para as empresas exportadoras atenderem a essas exigências. Um dos entrevistados da área de exportação da empresa $\mathrm{B}$ ressalta que, em razão do preço do produto, torna-se complicado exportar. As exportações em 2010 representaram, aproximadamente, 7\% das vendas das empresas contra 50\% em 2006/2007. Em 2011, as exportações das empresas cerâmicas, especialmente para os EUA, chegaram próximo de zero.

De forma geral, os entrevistados não veem a internacionalização das empresas como propulsora de práticas de Gestão Ambiental. Segundo eles, estes foram dois processos que caminharam separadamente. Para eles, as práticas ambientais funcionaram como argumentos de venda que propiciaram o aumento das exportações, mostrando a relação inversa, conforme o pressuposto assumido, e não confirmado, na pesquisa de Hrdlicka (2009).

As empresas, assim, admitem que o mercado externo pode trazer novas exigências e tendências para atitudes sustentáveis, mas não reconhecem que a internacionalização tenha sido fator de grande influência. Esse argumento corrobora a pesquisa de González, Sarkis e Adenso-Diaz (2008).

\section{DISCUSSÃO E CONSIDERAÇÕES FINAIS}

Esta pesquisa desenvolvida permitiu observar, por meio dos dados coletados, três grandes aspectos da gestão ambiental das empresas: (i) a concepção do produto, (ii) os processos principais, e (iii) as funções de apoio, tal como salientadas por Yang, Yang e Peng (2011). Dados obtidos sobre processo e os produtos puderam também ser confirmados pela observação durante a visita às fábricas.

Apesar do pressuposto inicial base, dado na pesquisa de Qi, Zeng et. al. (2011), quando se procurou contrastar a evolução da Gestão Ambiental das indústrias cerâmicas catarinenses com seu processo de internacionalização, percebeu-se, de acordo com os relatos dos entrevistados, que não há influência significativa entre a atuação no mercado externo, como indutor e a evolução das práticas de gestão ambiental das empresas, contrariando também a pesquisa de Cardoso et al (2008). De fato, para os entrevistados, os investimentos fabris, as adaptações de processos e o 
desenvolvimento de uma cultura voltada à sustentabilidade dependeu mais das variáveis socioeconômicas e legais brasileiras do que propriamente da demanda e exigência do mercado externo. Ainda assim, notou-se que as empresas focaram sua atuação e desenvolveram sua gestão ambiental buscando, primordialmente, a redução de custos e, ao mesmo tempo, procurando manter sua competitividade em relação, principalmente, a seus concorrentes nacionais. Esse processo, por consequência, mas não por deliberação, resultou, também, no atendimento das exigências do mercado internacional, conforme destacam Turolla e Lima (2010),

Cabe ressaltar, entretanto, que em uma área específica, a internacionalização acabou induzindo a gestão ambiental da empresa. Esta área é a de desenvolvimento de produtos. Nesse sentido, o contexto internacional influenciou e norteou os primeiros passos das empresas no desenvolvimento de produtos sustentáveis.

Para atender este segmento, as empresas desenvolveram grupos de produtos que passaram a atender as expectativas tanto do mercado internacional quanto do nacional. O primeiro grupo é aquele que pretende substituir com vantagens produtos naturais, muitos deles com riscos de extinção. Os maiores exemplos foram os lançamentos dos revestimentos cerâmicos que pretendem substituir madeiras e mármores, imitando-os. Muitos destes itens passaram a ser designados com o prefixo ECO, para bem caracterizar este diferencial. Nesta gama de produtos, destacam-se as séries Ecowood, Ecodecor, Ecoparquet e Econative da empresa a e os produtos Ecostone,E da empresa B.

Em um segundo grupo de produtos, as empresas procuraram inovar e apostar na redução de insumos (matérias-primas, energia, embalagens, etc.) além de facilitar sua instalação, notadamente nas reformas. Tratam-se dos produtos intitulados extrafinos. Estes produtos são mais finos e, consequentemente, economizam insumos. Além disto, e mais importante, apostam na facilidade da reforma, permitindo sua sobreposição a outros revestimentos. Nesse processo, economizam tempo, além de eliminar sujeira, entulhos e poluição típica das reformas e o que contribui para a sustentabilidade das obras em si. Compõem também este grupo de produtos, aqueles compostos por matérias-primas reutilizadas, oriundas do processo produtivo, além de outras inovações que não passam pelo processo de queima.

Assim, influência e a inspiração internacional parecem ter ocorrido menos no modelo e no sistema de sustentabilidade e muito mais no desenvolvimento de produtos, quesitos que atendem a preocupação do consumidor que busca produtos com maior componente e apelo sustentável.

Observa-se que o grande apelo é o econômico, em todo o processo descrito. Embora as demandas de quem exporta sejam mais exigentes, hoje isso, para as empresas, parece muito similar, tendo em vista o mercado global. Empresas americanas como a Lows e a Home Depot ou grandes clientes americanos não fazem auditoria. Em geral, há representantes que vem ao Brasil para aplicar um questionário junto às empresas com o intuito de observar a existência de fatores, tais como trabalho escravo, atendimento às exigências fiscais, às normas comerciais e ambientais e à solidez financeira. A questão ambiental é apenas um dos fatores levantados, para os quais não são exigidas as normas ISO 14.001. Já a Agência Brasileira de Promoção de Exportação e Investimentos (Apex), segundo os entrevistados, preocupa-se com a existência de certidões negativas para a participação em feiras internacionais. Assim, apesar da coincidência da evolução da gestão ambiental com a evolução da internacionalização das empresas, a partir do final da década de 1990 e início dos anos 2000, a pesquisa mostra que não foi a atuação internacional que levou as empresas a intensificarem suas ações ambientais. Isso é, principalmente, destacado pelo fato de acharem que a partir dos anos 2000 a própria legislação nacional adotou exigências equiparadas às normas internacionais. Desta forma, os entrevistados atrelam a evolução da gestão ambiental à globalização e aos próprios clientes e consumidores.

De forma geral, não é possível, portanto, afirmar categoricamente que a gestão ambiental das empresas esteja relacionada com sua atuação no mercado externo, mas sim com a busca pela competitividade global, contrariando os argumentos de González e González (2006) e confirmando os achados de González, Sarkis e Adenso-Diaz (2008). 
Os achados dessa pesquisa limitam-se à interpretação dos entrevistados acerca do ambiente internacional e de sua influência na gestão ambiental, assim como a percepção dos próprios pesquisadores. Para minimizar esses problemas, a triangulação foi utilizada como forma de aumentar a validade da pesquisa. Os dados também se limitam ao setor cerâmico, o que desperta o interesse para estudo em outros setores.

Espera-se que esse trabalho possa fornecer importantes subsídios para o debate, ainda novo, na área, sobre a relação entre a internacionalização e a gestão ambiental empresarial, para a indústria pesquisada e também para o enriquecimento dos fatores que condicionam a gestão ambiental das empresas. Da mesma forma, esta pesquisa pode contribuir para o estudo das políticas públicas na área ambiental, tendo em vista o importante papel que a regulamentação governamental exerce sobre a ação das empresas.

\section{REFERÊNCIAS}

Alperstedt, G. D., Quintella, R. H., Souza, L. R. (2010) Estratégias de gestão ambiental e seus fatores determinantes: uma análise institucional. Revista de Administração de Empresas, 50, 170186.

Alperstedt, G. D., Moraes, M. C. B., Spohr, N., Sarubbi, F. (2010) A internacionalização de empresas cerâmicas brasileiras: uma análise institucional. Perspectivas Contemporâneas, v. esp, $121-148$.

Anfacer - Associação Nacional dos Fabricantes de Cerâmica para Revestimentos (2011). Recuperado em: 6 jun.2011, de: http://www.anfacer.org.br.

Barbieri, J.C. (2006) Gestão ambiental empresarial: conceitos, modelos e instrumentos. São Paulo: Saraiva.

Cardoso, A. C. F., Caridade, A. V. S., Hourneaux Jr, F., Kruglianskas, I. (2008) O processo de internacionalização e os aspectos socioambientais: o caso Embraer. Revista de Administração, 1, 57-70.

Darnal, N., Henriques, I., Sadorsky, P. (2008) Do environmental management systems improve business performance in na international setting? Journal of International Management, 14.

Dreher, M., Amal, M., Souza, V. S. F. de. (2007) A influência da responsabilidade sócio-ambiental no processo de internacionalização: o caso da Electro Aço. Revista Ciências da Administração, 9 (19).

Eidat, Y., Kelly, A., Roche, F., Eydat, H. (2008) Green and competitive? An empirical test of the mediating role of environmental innovation strategy. Journal of World Business, 43.

Ferrari, K. R. (2000) Aspectos ambientais do processo de fabricação de placas de revestimentos cerâmicos (via úmida), com ênfase nos efluentes líquidos. São Paulo. IPEN. Tese para obtenção do grau de Doutor em Ciências na Área de Tecnologia Nuclear - Materiais.

Fiesp - Federação das Indústrias do Estado de São Paulo. (2008) Guia técnico ambiental da indústria de cerâmica branca e de revestimento - série $P+L$. Governo do Estado de São Paulo. Secretaria do Meio Ambiente CETESB - Companhia de Tecnologia de Saneamento Ambiental.

Flick, U. Introdução à pesquisa qualitativa. (2009). Porto Alegre, Artmed. 
González, J. G. Sarkis, B. Adenso-Díaz, P. (2008) Environmental management system certification and its influence on corporate practices: Evidence from the automotive industry. International Journal of Operations \& Production Management, 28 (11), 1021-1041.

González, J. G.; González, B. (2006) O. G. A review of determinant factors of environmental proactivity. Business Strategy and the Environment, 15, 87-102.

Harrison, A. L., Dalkiran, E., Elsey, E. (2000) International business: global competition from an european perspective. Bath: Oxford University Press.

HART, S. L. The natural resource-based view of the firm (1995). Academy of Management Review, 20(4), 986-1014.

Hart, S.L., Dowell, G. (2010) A natural-resource-based view of the firm: fifteen years after. Journal of Management, Special Issue: Twenty Years of Resource-Based Theory.

Hrdlicka, H. (2009) As boas práticas de gestão ambiental e a influência do desempenho exportador: um estudo sobre as grandes empresas exportadoras brasileiras. USP/FEA, São Paulo.

Hunt, C. B., Auster, E. R. (1990) Proactive environmental management: avoiding the toxic trap. Sloan Management Review. EUA: Putnam, Hayes \& Bartlett.

Lee, S. Y., Rhee, S. K. (2006). The change in corporate environmental strategies: a longitudinal empirical study. Management Decision, 45 (2).

Miller, D., Friesing, P. H. (1982) The longitudinal analyses of organizations: a methodological perspective. Management Science, 28(9), 1013-1033.

Qi, G.Y., Zeng, S.X., Tamb, C.M., Yin, H.T., Wu, J.F., Daí, Z.H. (2011) Diffusion of ISO 14001 environmental management systems in China: rethinking on stakeholders' roles. Journal of Cleaner Production, 19 (11), 1250-1256.

Richardson, R.J. (1999). Pesquisa social: métodos e técnicas. São Paulo: Atlas.

Sanches, C.S. (2000) Gestão ambiental proativa. Revista de Administração de Empresas, 40 (1).

Turolla, F.A., Lima, M.F.F. de. (2010) Internacionalização e sustentabilidade. GV Executivo, São Paulo, 9(1), 18-21.

Uehara, T.H.K. et al. (2010) Pesquisas em gestão ambiental: análise de sua evolução na Universidade de São Paulo. Ambiente \& Sociedade, 13 (1), 165-185.

Yang, C.C., Yang, K.J., Peng, S.Y. (2011) Exploration strategies and key activities for the system of environmental management. Total Quality Management, 22 (11), 1179-1194.

Data da submissão: 28/06/2013

Data da publicação: 30/08/2013 